\title{
W-types in homotopy-type theory - CORRIGENDUM
}

\author{
BENNO VAN DEN BERG and IEKE MOERDIJK
}

Received 30 November 2015; revised 14 March 2016

doi:10.1017/S0960129514000516, Published by Cambridge University Press, 24 November 2014.

In the article below, Theorem 3.4 requires the additional assumption that $A$ is $\mathrm{Kan}$ as well. Indeed, the inductive proof as given only shows that if $W(f)_{<\alpha}$ is a Kan complex, then $W(f)_{<\alpha+1} \rightarrow A$ is a Kan fibration.

\section{References}

Berg, B. van den and Moerdijk, I. W-types in homotopy type theory. Mathematical Structures in Computer Science. Published by Cambridge University Press, 24 November 2014. doi: 10.1017/ S0960129514000516 